\title{
Designing a SuRvey Study to MEASure THE DIVERSITY OF DIGITAL LEARNERS
}

\author{
Pengiran Shaiffadzillah Pengiran Omarali \\ School of Education, Environment and Development, University of Manchester, \\ United Kingdom
}

\begin{abstract}
This article describes the design of a quantitative study that aims to gather empirical data on the different types of digital learners in a student population, inclusive of the elusive digital natives who purportedly exist in settings laden with digital technology. The design of this study revolves on the impetus in mapping the diversity of digital learners, followed by elucidations on the research design and methods that are to be employed, its accompanying data analysis, ethical considerations and an elaboration of the measures that are taken in ensuring validity and reliability.
\end{abstract}

\section{KEYWORDS}

Survey design, digital learners, digital natives

\section{INTRODUCTION}

According to Prensky, the digital natives are "a generation born after the 1980s surrounded by and immersed in digital technologies such as computers, video games, cell phones and other toys and tools of the digital age" [1]. One main caveat of this conjecture is that the criteria and conceptualization used in any digital native survey might not reflect the actual numbers at ground-level particularly within the context of students, because "a serious problem with the concept of the digital natives is that it is an analogue of either/or binaries rather than a continuum" [2]. Furthermore, "a significant body of international research has largely debunked the idea of a uniformly technically savvy generation" [3] but still the term has persevered through the moral panic generated by the media [4]. One research established that "learners, regardless of age, are on a continuum of technology access, skill, use and comfort" [5].

The hypothesis here is that digital native is the extreme archetype of a more digitally diverse student population. For educational technology to be successful and in preventing a one-size-fitsall approach, there is a need to map this diversity. It is then the onus of education providers that if we are to be proponents of the much contested digital native concept, it must not be by virtue of blind faith or moral panic but rather by establishing empirical data that would enable us to map out the whole continuum of digital learners. The attained information will establish a better understanding of our students and consequently empower policymakers to make informed decisions in providing a digitally enhanced education system that is holistic and inclusive for all.

\section{RESEARCH DESIGN}

\subsection{Research Hypothesis}

As previously mentioned, the hypothesis for this research is that the digital learner population is diverse and not limited to one archetype (i.e. digital natives). As the degree of digital learner diversity is oftentimes unknown, this study is thus a fact-finding mission that intends to "gather large-scale data from as representative a sample population as possible in order to say with the measure of statistical confidence that certain factors cluster together" [6]. 


\subsection{Designing the Survey Research}

The most appropriate approach is thus the quantitative survey design as it "provides a quantitative or numeric description of trends, attitudes, or opinions of a population by studying a sample of that population" [7]. Considering the learner population size, the survey is cross-sectional in order to generate "a 'snapshot' of a population at a particular point in time" [6]. The cross-sectional design is a very reliable approach because "they are easily replicated and the quantifiable data can be verified by others" [8], "the survey produces large amounts of statistical information, relatively quickly and cheaply" [8], and that "they can be aimed at large groups of people thus making them more representative of a wider society" [8].

Surveys profiling a cross section of society "usually takes the form of a self-completion questionnaire" [8]. A similar research in identifying digital natives employed a survey design and it was concluded as reliable and valid [9]. The survey design therefore uses a self-completion questionnaire as the primary data generation method. An added value is that questionnaires can be "extremely efficient at providing large amounts of data, at relatively low cost, in a short period of time" [6]. The numerical data this research intends to collate needs to be able to gauge the level of experience, familiarity and skills of the students when interacting with the digital world in order to describe diversity based on the demographic, descriptive information, and evaluated information. Akin to a test, a section of the questionnaire includes samples of 1) the audio, graphic and animated media that exist in the internet as well as 2) the processes performable in the internet with differing levels of difficulty. A variant questionnaire type that allows this feature is the internet-based questionnaire. However, a paper-based version is deemed not practical, as it cannot replicate these features.

The frame of the self-administered questionnaire is HTML-based and thus accessible via any web browser found on a computer or mobile device. Significant to this accessibility is that respondents are simply provided with a URL address and a password or access token to limit access to only the intended sample [6]. It can be completed outside of school hours where ever Internet is accessible and in the leisure of one's own time [6].

On the researcher side, the advantage of an Internet questionnaire is its ability to automatically update and process data as soon as receiving response, generating tabulated and graphical analytics of the data collected [6] to the extent of performing formulaic calculations for live analysis if needed. For this particular research, and in light of the features intended to be included in the questionnaire, the online survey creator Lime Survey as the design frame with additional PHP programming to allow for an enhanced interaction with certain multimedia based items. The items are thematically divided into two sections, and each in turn divided into two nominal and ordinal subsections. The section on learner characteristics comprises of demographic items and questions on Internet experience. The section on a learner's digital competencies assesses learners' familiarity with Internet jargon and literacies as well as competencies in operating and navigating the Internet.

\subsection{Demographic Items}

This questionnaire section contains closed-ended items that intend to superimpose the characteristics of a respondent to that of a digital learner as adapted from Teo's Digital Native Assessment Scale (DNAS) [9]. The DNAS collects data on the digital competency of a student, as well as on the household presence and personal ownership of technologies such as computers and mobile devices. These provide information if a respondent has been immersed in technologies [10]. 


\subsection{Items on Internet Experience}

Items in this section concerns with the duration of immersion to general activities of the Internet such as blogging, downloading media and purchasing apps. This section collects ordinal data and consists of items each with a complementary sub-item. The reply input on the main item either invokes or skips the sub-item. This is a web-survey feature called skip logic [11]. Items are in the form of 5-point Likert scales.

\subsection{Items on Internet Jargon and Literacies}

The items in this section tests respondents' level of familiarity towards specific sounds, graphics and animations that are prevalent on the Internet. Items in this section collect ordinal data and employ multiple-choice questions requiring either single-answer mode or multiple-answer mode.

\subsection{Items on Internet Processes}

The items in this section comprise of web-quests to test the level of expertise in navigating through the Internet to access information. A web-quest is "an inquiry-oriented activity in which some or all of the information that learners interact with comes from resources on the Internet" [12]. One example is a low difficulty task of uploading into the questionnaire a screen capture of a virtual world (e.g. MineCraft, World of Warcraft, SecondLife, Kodu). Another example is Internet Easter Egg quests, which require respondents to find information purposely hidden in the Internet realm.

Items in this section are open-ended numerical inputs but the hidden back-end process involves the questionnaire computing correct answers as positive responses and incorrect answers as negative responses, thereby actually collecting dichotomous nominal data. Respondents also have the option to request another question to fulfil the minimum quota of items to be responded.

\subsection{Conducting the Survey}

Piloting the questionnaire beforehand improves the "reliability, validity and practicability of the questionnaire" through getting feedback generally on how items fit the purpose of the research [6]. Items are also to be subjected to Cronbach's alpha analysis to determine internal consistency [6]. Apart from items under 'learner characteristics' which have already been validated through a study with $n=1000$ sample [9], items under the 'learner's competencies' theme are generically based on elements under digital literacy frameworks [13], [14].

\subsection{Methods of Data Analysis}

One advantage of using Internet questionnaires is that descriptive analysis are done automatically from within the questionnaire programme [6] and therefore measures of central tendency, variability and summation of these values are completed the moment it reaches a predetermined sample size. Altogether there are expectedly two data sets based on the questionnaire's themes, which are 1) learner characteristics and 2) learner's digital competencies. Table 1 below illustrates the segmentation of items.

Table 1. Item segments in the questionnaire

\begin{tabular}{|l|l|}
\hline (1) Learner characteristics & (2) Learners' digital competencies \\
\hline Basic demographic information & Knowledge of Internet jargon \\
\hline Ownership of digital devices & Internet literacy skills \\
\hline Internet experience & Inquiry-oriented Internet tasks \\
\hline
\end{tabular}


In order for the data to be further organised into segments, the two data sets are to be transferred to SPSS to undergo cluster analysis so as to derive these unknown segments. Cluster analysis "enables the researcher to group together similar and homogeneous subsamples of people" [6]. Thus, data set (1) is plotted against data set (2) using a scatter plot. However, the scatter plot is not used to establish correlation or linear/non-linear relationships. Instead, the mapping of the sample is based on sample density, similar to, if not the exact method of, density-based clustering which uses density as indicators of clusters, and their positions in the scatter plot is not linear but rather arbitrary [15].

The design of this research takes necessary measures to ensure that the data it generates is protected from threats and thus be valid and reliable. For example, piloting a questionnaire with a larger list of items provides an opportunity to amend the instrument and remove items that exhibit collinearity, as well as ensuring instrument reliability through correlating items with Cronbach's alpha to check for internal consistency [6].

To ensure content validity, the items in the questionnaire are based on the seven elements of the digital literacy framework, which cover all the processes involved in interacting with information from the Internet. This makes certain that the questionnaire is "a fair representation of the wider issue under investigation (and its weighting) and that the elements chosen for the research sample are themselves addressed in depth and breadth" [6].

The study ensures external validity through its sample with a strong confidence interval to the population it represents through generalisation that if the research can be generalised to the target population "according to rules of statistical inference" [16], then it has external validity. Issues of bias are also addressed through the sampling. Through using a probability sampling strategy, biases are minimised in its attempts to be representative of the whole population [6].

\section{Conclusions}

This survey is hoped to provide empirical information that not only will be useful to guide ICT initiatives but also will be the first data set on the local student population that can be used as baseline data. It is hoped that this research will be a prerequisite and the first of a series of crosssectional studies to generate data over time on the other cohorts of the population. This approach is an attribute of a longitudinal study whereby I can use "repeated cross-sectional studies, which are carried out regularly, each time using a largely different sample or a completely new sample [17] or use the same sample over time [6]. This data when combined will ultimately produce a detailed map of digital learners not arranged in any hierarchical way but clustered into their own niches of diverse digital competencies.

\section{REFERENCES}

[1] Prensky, M. (2001). Digital natives, digital immigrants part 1, On the horizon, 9 (5), pp. 1-6.

[2] Brown, C. \& Czerniewicz, L. (2010). Debunking the 'digital native': beyond digital apartheid, towards digital democracy, Journal of Computer Assisted Learning, 26 (5), pp.357-369.

[3] Bennett, S. (2012) 'Digital natives'. In Yan, Z. (ed.), Encyclopedia of Cyber Behavior: Volume 1, United States: IGI Global, pp.212-219.

[4] Bennett, S., Maton, K. \& Kervin, L. (2008). 'The 'digital natives' debate: A critical review of the evidence', British Journal of Educational Technology, 39 (5), pp.775-786.

[5] Bullen, M. \& Morgan, T. (2011). 'Digital learners not digital natives', La Cuestión Universitaria, 7, pp.60-68. 
[6] Cohen, L., Manion, L. \& Morrison, K. (2011). Research Methods in Education. $7^{\text {th }}$ edn. Oxon: Routledge.

[7] Creswell, J. W. (2014). Research Design: Qualitative, Quantitative, \& Mixed Method Approaches. $4^{\text {th }}$ edn. London: Sage.

[8] McNeill, P. \& Chapman, S. (2005). Research methods. $3^{\text {rd }}$ edn. Oxon: Routledge.

[9] Teo, T. (2013). An initial development and validation of a Digital Natives Assessment Scale (DNAS), Computers and Education, 67, pp.51-57.

[10] Autry, A.J. \& Berge, Z. (2011). Digital natives and digital immigrants: getting to know each other, Industrial and Commercial Training, 43(7), pp.460-466.

[11] Peytchev, A., Couper, M. P., McCabe, S. E. \& Crawford, S. D. (2006). Web survey design paging versus scrolling, Public Opinion Quarterly, 70(4), pp.596-607.

[12] Dodge, B. (1995). WebQuests: a technique for Internet-based learning, Distance educator, 1(2), pp.10-13.

[13] Martin, A. (2005). DigEuLit-A European framework for digital literacy: A progress report, Journal of eLiteracy, 2(2), pp.130-136.

[14] Educational Testing Service (2007). Digital Transformation: A Framework for ICT Literacy. ETS. Available:

http://www.ets.org/Media/Tests/Information_and_Communication_Technology_Literacy/ictreport .pdf.

[15] Kriegel, H. P., Kröger, P., Sander, J., \& Zimek, A. (2011). Density-based clustering, Interdisciplinary Reviews: Data Mining and Knowledge Discovery, 1(3), pp.231-240.

[16] Robson, C. (2011). Real World Research. $3^{\text {rd }}$ edn. West Sussex, UK: Wiley.

[17] Ruspini, E. (2002). Introduction to Longitudinal Research. London: Routledge.

\section{Author}

Before taking an administrative position in the executive management of education under the Ministry of Education Brunei Darussalam, the author was an English teacher for 7 years teaching English as a Second Language to secondary level students in Brunei Darussalam. In 2005, he attained a Bachelors of Art in Education degree with a TESL specialisation from Universiti Brunei Darussalam, followed by a Masters Degree in Educational Technology and Teaching English as a Second or Other Language from the University of Manchester, United Kingdom in 2008. As of 2017, he is a final year Ph.D. candidate at the University of Manchester, United Kingdom reading Education with a research focus on educational technology and

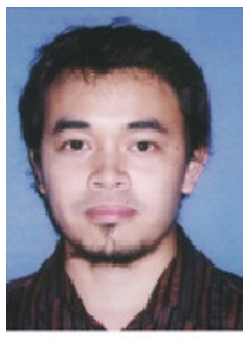
online learning. 